\title{
First evidence of a large CHEK2 duplication involved in cancer predisposition in an Italian family with hereditary breast cancer
}

\author{
Gianluca Tedaldi ${ }^{*}$, Rita Danesi ${ }^{1}$, Valentina Zampiga ${ }^{1}$, Michela Tebaldi ${ }^{1}$, Lucia Bedei ${ }^{2}$, Wainer Zoli ${ }^{1}$, Dino Amadori ${ }^{1}$,
} Fabio Falcini ${ }^{1}$ and Daniele Calistri ${ }^{1}$

\begin{abstract}
Background: CHEK2 is a multi-cancer susceptibility gene whose common germline mutations are known to contribute to the risk of developing breast and prostate cancer.

Case presentation: Here, we describe an Italian family with a high number of cases of breast cancer and other types of tumour subjected to the MLPA test to verify the presence of BRCA1, BRCA2 and CHEK2 deletions and duplications. We identified a new 23-kb duplication in the CHEK2 gene extending from intron 5 to 13 that was associated with breast cancer in the family. The presence and localisation of the alteration was confirmed by a second analysis by Next-Generation Sequencing.

Conclusions: This finding suggests that CHEK2 mutations are heterogeneous and that techniques other than sequencing, such as MLPA, are needed to identify CHEK2 mutations. It also indicates that CHEK2 rare variants, such as duplications, can confer a high susceptibility to cancer development and should thus be studied in depth as most of our knowledge of CHEK2 concerns common mutations.
\end{abstract}

Keywords: CHEK2, Duplication, Breast cancer, Hereditary cancer, MLPA, Next-generation sequencing

\section{Background}

Breast cancer is the most frequent invasive cancer in women and its incidence is increasing in Western countries [1]. Hereditary breast cancer $(\mathrm{HBC})$ represents only $5-10 \%$ of all breast cancer cases. The principal genes involved in the risk of breast cancer are $B R C A 1$ and $B R C A 2$, which account for about $20-50 \%$ of all HBC cases. To date, other low-penetrance genes, correlated with the risk of breast cancer, have been identified, such as $A T M$, BRIP1, CDH1, PALB2 and CHEK2 [2].

The checkpoint kinase 2 gene (CHEK2, MIM\# 604373) is located in 22q12.1 and is the human homolog of RAD53 (Saccharomyces cerevisiae) and CDS1 (Schizosaccharomyces pombe).

CHEK2 protein is located in the nucleus and consists of 543 amino acids with three main domains: a SQ/TQ

\footnotetext{
* Correspondence: gianluca.tedaldi@irst.emr.it

'Istituto Scientifico Romagnolo per lo Studio e la Cura dei Tumori (IRST) IRCCS, Meldola, Italy

Full list of author information is available at the end of the article
}

cluster domain (aa 20-75), a forkhead-associated domain (aa 115-165) and a Ser/Thr kinase domain (aa 225-490) [3].

In response to DNA double-strand breaks, CHEK2 protein is phosphorylated by ATM and catalyses the phosphorylation of $\mathrm{CDC} 25 \mathrm{C}$, down-regulating it and preventing entry into mitosis [4].

Furthermore, after DNA damage, CHEK2 phosphorylates the p53 tumour suppressor protein and prevents its degradation, leading to cell cycle arrest in G1 [5].

Under gamma irradiation, CHEK2 also phosphorylates BRCA1 on Ser-988, activating the DNA repair process [6]. Finally, CHEK2 has been shown to induce apoptosis independently of p53, via phosphorylation of the PML tumour suppressor protein [7].

The first germline mutations identified in the CHEK2 gene were associated with Li-Fraumeni syndrome (MIM\# 609265), a disease characterised by high occurrences of sarcomas, breast cancer, brain tumours, acute leukaemia and adrenocortical tumours [8]. 
Bell identified CHEK2 mutations in three families, including the mutation 1100delC in the kinase domain, resulting in premature termination [9].

This cytosine deletion at nucleotide 1100 of CHEK2 sequence was also identified in two Finnish families with atypical Li-Fraumeni syndrome due to the lack of sarcomas or childhood cancers [10].

Subsequently, the same mutation was identified in $B R C A 1 / 2$-negative families with hereditary breast cancer and it has been estimated that it results in an approximately two-fold increase of the risk of breast cancer in women and a ten-fold increase of risk in men [11]. The 1100delC mutation shows a high prevalence in northern Europe and its homozygosity confers a fourfold increased risk of breast cancer in women [12].

Dong found 28 CHEK2 germline mutations among 578 men with prostate cancer, suggesting that CHEK2 mutations play a role in prostate cancer development [13], and Cybulski found common mutations, such as 1100delC, IVS2 + 1G > A and I157T, in families with hereditary prostate cancer [14].

More recently, common mutations in CHEK2, such as 1100delC, I157T and IVS2 + 1G > A, have been associated with different types of cancer [15-17], but the association of CHEK2 mutations with Li-Fraumeni syndrome has been questioned because of different phenotypes in Li-Fraumeni patients and CHEK2 mutation carriers [18].

In 2006, a novel $5.6 \mathrm{~kb}$ deletion of exons 9 and 10 was discovered in two families of Czechoslovakian ancestry with hereditary breast and ovarian cancer and the alteration has also been detected in 8 out of 631 patients with breast cancer and in none of the 367 controls from the Czech and Slovak Republics [19]. Cybulski and coworkers also detected this deletion in 15 out of 1864 males with unselected prostate cancer and in 4 out of 249 males with familial prostate cancer and concluded that this alteration doubles the risk of prostate cancer in men and quadruples the risk of familial cases [20]. However, this large deletion seems to be a founder mutation present only in Slavic populations.
Recently, in France, 16 CHEK2 mutations were found in 507 cases of BRCA1/2-negative hereditary breast cancer. Nine of these variants were novel and no mutation hotspots were identified, suggesting that CHEK2 mutations are spread throughout the gene and that CHEK2 mutation screening in populations where the common founder mutations are rare must consider the entire coding region [21]. To date, less than 100 mutations in the CHEK2 gene have been identified: the Human Gene Mutation Database v. Professional 2013.4 contains 55 missense/nonsense mutations, 2 gross deletions, 11 small deletions, 1 small insertion, 3 splice-site mutations and 2 mutations in regulatory regions.

\section{Case presentation}

We report the identification of the first large duplication in the CHEK2 gene in a family with a history of breast cancer, detected during a study on hereditary breast cancer. The study was performed in accordance with the principles of Good Clinical Practice and the ethical standards laid down in the Declaration of Helsinki and approved by the IRST Ethical Committee (CE IRST IRCCS-AVR, protocol 2207/2012).

The first family member who came to our attention through our regional screening protocol for breast cancer was a woman aged 36 (III-4) who did not have cancer but had a high family incidence of breast cancer (Figure 1). Her mother (II-3) had bilateral breast cancer at 46 years old and 56 years old; three aunts had breast cancer at 70 years old (II-5), 50 years old (II-9) and 40 years old (II-11); and another aunt died of ovarian cancer at 40 years old (II-1). The grandfather of the proband (I-1) died of prostate cancer at 80 years old. Furthermore, the brother of the proband (III-5) has a clinical suspicion of neurofibromatosis for which he is under investigation and a cousin's daughter (IV-1) developed leukaemia at 3 years old.

The proband III-4 was subjected to mutation analysis of $B R C A 1 / 2$ : after her informed consent was obtained, we collected peripheral blood of III-4 and we extracted

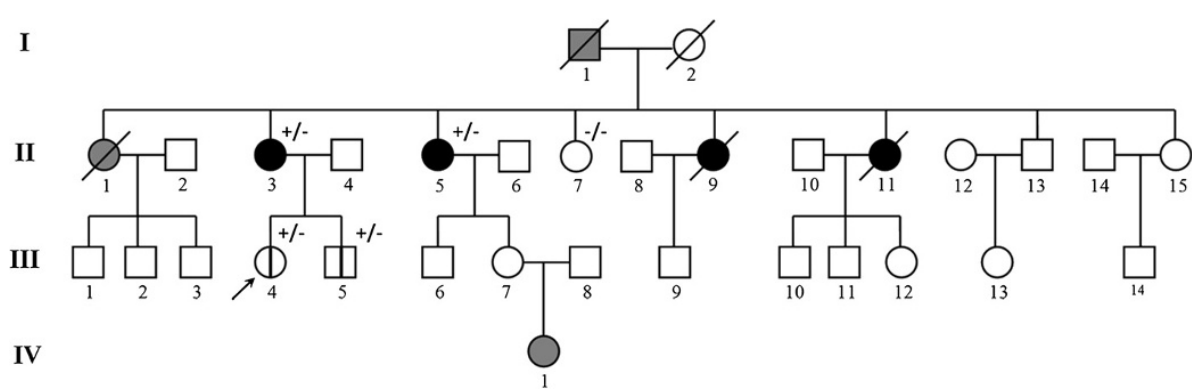

Figure 1 Pedigree of the family with duplication in CHEK2. Black symbols indicate breast cancer and grey symbols indicate other type of tumours (see text); the proband is indicated by an arrow; members of the family submitted to the genetic test are indicated by $+/-$ for mutation carriers or $-/-$ for non-mutation carriers; the vertical bar indicates unaffected mutation carriers. 
the DNA from leukocytes using the QIAamp DNA mini kit (Qiagen, Hilden, Germany). All the coding exons and flanking introns of $B R C A 1$ and $B R C A 2$ were amplified by PCR with Ex Taq DNA polymerase (Takara, Otsu, Japan) and subjected to Sanger sequencing using the BigDye Terminator v3.1 (Life Technologies, Carlsbad, $\mathrm{CA})$. The sequences were analysed by capillary electrophoresis on the 3130 Genetic Analyzer (Life Technologies).

The BRCA1/2 mutation test on III-4 detected a number of variants in BRCA1 that were classified as polymorphisms on the basis of the Universal Mutation Database (http://umd.be/BRCA1/): c.2082C > T (rs1799949), c.2311 T > C (rs16940), c.2612C > T (rs799917), c.3113A > G (rs16941) in exon 11, c.4308 T > C (rs1060915) in exon 13 and c.4837A > G (rs1799966) in exon 16.

The same polymorphisms had also been found in her mother (index case), who had undergone the BRCA1/2 mutation test at another laboratory.

These variants could not explain the high familiarity of breast cancer in this family and we, therefore, conducted on III-4 the Multiplex Ligation-dependent Probe Amplification analysis (MLPA) for deletions/duplications of all BRCA1/2 exons with BRCA1-P002-C2 and BRCA2P045-B3 (MRC Holland, Amsterdam, the Netherlands).

In particular, the BRCA2-P045 kit contains probes for all the exons of $B R C A 2$ and three additional probes for the CHEK2 gene: a probe for the promoter region, a probe specific to the 1100delC mutation [9] and a probe for exon 9, whose deletion has been detected in families with hereditary prostate and breast cancer $[19,20]$.

The samples were loaded onto the 3130 Genetic Analyzer (Life Technologies) and the results were analysed using Coffalyser.net software (MRC-Holland). The software divides the normalised peak areas of the patient by the average peak areas of reference samples (four reference samples from healthy individuals were introduced in each run). The software gives a value for each exon that is normal between 0.7 and 1.3 and indicates a deletion under 0.7 or a duplication over 1.3. The analysis of the results with Coffalyser.net showed a duplication (value of 1.68) for the exon 9 of CHEK2 in patient III-4 (data not shown).

In order to confirm the data and to verify the extension of the duplication, we performed the analysis of the sample with the CHEK2-P190-B1 kit (MRC Holland), which contains probes for each CHEK2 exon. The new analysis with Coffalyser.net showed that the duplication extends from exon 6 to exon 13 (NM_007194.3) with ratios of 1.29-1.51 (Figure 2A).

The MLPA analysis of CHEK2 was extended to four other members of the family who, after providing their informed consent, agreed to participate in the test (II-3, II-5, II-7 and III-5 in Figure 1). The mother of the proband (II-3) and her aunt (II-5), both of whom had had breast cancer, had the same duplication in CHEK2. The brother of the proband (III-5), who had multiple subcutaneous cysts similar to neurofibromas, had the same duplication as the sister. The aunt II-7, who had never had cancer, did not have the duplication.

In order to confirm the duplication and its exact size (the MLPA kits used in our experiments do not provide information on introns) with another method, the region containing the breakpoint was amplified. For this purpose, we designed a primer forward that anneals before exon 13 (5'-GTCTGCTGACTCCGTGATGA) and a primer reverse that anneals after exon 6 (5'-TGGGGTTA CAGTGGGGATTA). Due to their specific design, these two primers only generate a PCR product in patients who have the duplication and do not generate any product in the absence of duplication (Figure 2B).

The PCR products were analysed by agarose electrophoresis and the ethidium bromide staining showed a fragment of about $6 \mathrm{~kb}$ in size, present only in DNA from patients with the duplication and not in wild type individuals and in normal human DNA, used as a control (Figure 2C).

In order to verify the exact position of the breakpoint, we sequenced the amplicon by loading it onto the NextGeneration Sequencing platform Miseq (Illumina, San Diego, CA) using the Nextera XT kit (Illumina). The analysis of the results with Miseq Reporter 2.2.29 software (Illumina) showed that the region duplicated was almost $23 \mathrm{~kb}$ and that it extended from intron 5 at position 29111154 to intron 13 at position 29088207 (NCBI RefSeq: NC_000022.10).

\section{Conclusions}

In this study, we report the identification of the first large germline duplication in CHEK2 gene. This finding suggests that CHEK2 alterations could be more heterogeneous than expected and that it is important also to perform the research for duplications and deletions of CHEK2 gene by techniques such as MLPA, as these alterations cannot be detected by direct sequencing.

The presence and localisation of the duplication was confirmed by a second method, reinforcing the fact that this duplication was not an artefact caused by the presence of CHEK2 pseudogenes [22]. We evaluated the effect of the duplication and found that it created a frameshift at codon 488 in the kinase domain involved in the interaction of the protein with its targets and in the activation of the repair process after DNA damage, resulting in a premature termination at codon 503. The alteration reported here has not been detected in any of the other 244 $B R C A 1 / 2$-negative patients with a family history of breast and ovarian cancer analysed with MLPA in our laboratory, suggesting that this duplication is a rare variant and it is 


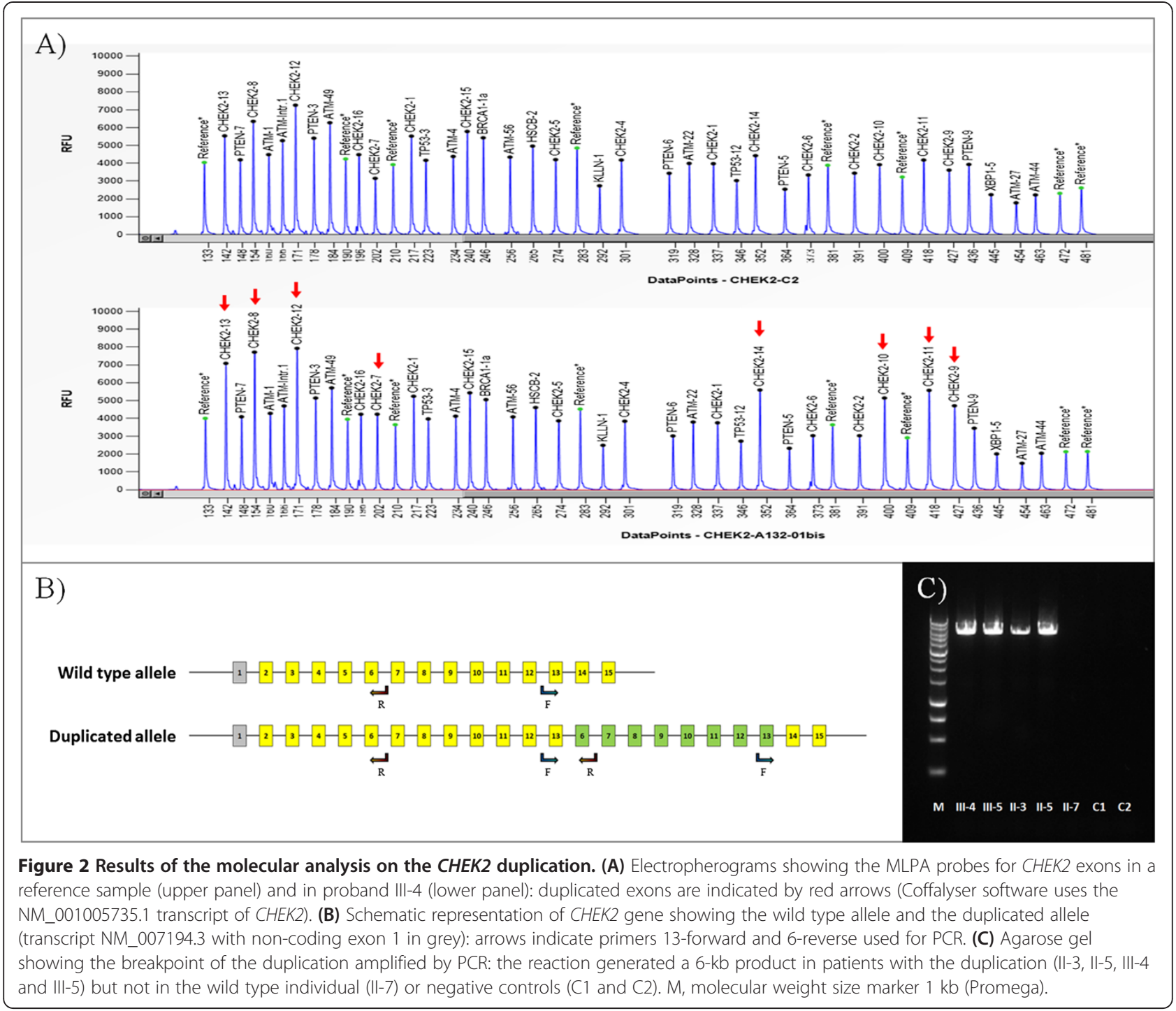

conceivable that it could contribute in an appreciable manner to cancer development.

Although we identified the CHEK2 duplication in a family with a prevalence of breast cancer, two of the carriers of the duplication were unaffected individuals (III-4 and III-5 in Figure 1). All of the patients with the CHEK2 duplication have been placed on a surveillance protocol that differs according to age and sex: the young unaffected woman (III-4 in Figure 1) is monitored by breast ultrasound and clinical examination every 6 months and by mammography every two years, while her mother and aunt (II-3 and II-5 in Figure 1) have been placed on a different surveillance protocol that comprises an annual breast ultrasound and mammography. Her unaffected brother (III-5 in Figure 1) is being monitored for prostate and breast cancer and undergoes annual PSA testing and breast ultrasound.
Some family members had different tumours, such as prostate cancer, ovarian cancer and leukaemia. Unfortunately, it was not possible to conduct the test on these patients to confirm the association of the duplication with these tumours because they had already died or had not reached the legal age for genetic testing.

CHEK2 has been described as a low-penetrance gene because its inherited mutations appear less severe, leading to an increase in the risk of breast cancer in women $[11,12]$ and prostate cancer in men $[13,14,20]$. These observations refer to commonly identified mutations but this case report appears to suggest that rare CHEK2 mutations, such as large duplications, can also be detected and could determine a higher than expected increase in the risk of cancer. For this reason, further studies are required in order to investigate the mechanisms by which rare mutations in CHEK2 participate in tumour development. 


\section{Consent}

Written informed consent was obtained from the patients for publication of this Case report and any accompanying images. A copy of the written consent is available for review by the Editor of this journal.

\section{Abbreviations}

HBC: Hereditary breast cancer; Aa: Amino acid; SQ/TQ: Serine-glutamine/ treonine-glutamine; MLPA: Multiplex ligation-dependent probe amplification.

\section{Competing interests}

The authors declare that they have no competing interests.

\section{Authors' contributions}

GT carried out the molecular genetic studies, was involved in all steps of data analysis and manuscript writing; RD was involved in the patient recruitment and in the clinical follow-up and helped to draft the manuscript; VZ was involved in the data analysis and helped to draft the manuscript; MT provided laboratory support in molecular genetic studies; LB was involved in patient recruitment and provided clinical data; WZ was involved in the conception and design of the study and critically reviewed the manuscript: DA and FF were involved in the conception and design of the study; DC was directly involved in the conception and design of the study, supervised all the steps of the analysis and coordinated manuscript writing. All authors read and approved the final manuscript.

\section{Acknowledgments}

The authors would like to thank the family members for participating in the genetic analysis and Ursula Elbling for editing the manuscript.

\section{Author details}

${ }^{1}$ Istituto Scientifico Romagnolo per lo Studio e la Cura dei Tumori (IRST) IRCCS, Meldola, Italy. ${ }^{2}$ Cancer Prevention Unit, Morgagni-Pierantoni Hospital, Forlì, Italy.

\section{Received: 29 October 2013 Accepted: 25 June 2014}

Published: 1 July 2014

\section{References}

1. Jemal A, Center MM, DeSantis C, Ward EM: Global patterns of cancer incidence and mortality rates and trends. Cancer Epidemiol Biomarkers Prev 2010, 19(8):1893-1907.

2. Gage M, Wattendorf D, Henry LR: Translational advances regarding hereditary breast cancer syndromes. J Surg Oncol 2012, 105(5):444-451.

3. Bartek J, Falck J, Lukas J: Chk2 kinase: a busy messenger. Nat Rev Mol Cell Biol 2001, 2(12):877-886.

4. Matsuoka S, Huang M, Elledge SJ: Linkage of ATM to cell cycle regulation by the Chk2 protein kinase. Science 1998, 282(5395):1893-1897.

5. Chehab NH, Malikzay A, Appel M, Halazonetis TD: Chk2/hCds1 functions as a DNA damage checkpoint in G1 by stabilizing p53. Genes Dev 2000, 14(3):278-288.

6. Lee JS, Collins KM, Brown AL, Lee $\mathrm{CH}$, Chung JH: hCds1-mediated phosphorylation of BRCA1 regulates the DNA damage response. Nature 2000, 404(6774):201-204

7. Yang S, Kuo C, Bisi JE, Kim MK: PML-dependent apoptosis after DNA damage is regulated by the checkpoint kinase hCds1/Chk2. Nat Cell Biol 2002, 4(11):865-870.

8. Li FP, Fraumeni JF Jr: Soft-tissue sarcomas, breast cancer, and other neoplasms. A familial syndrome? Ann Intern Med 1969, 71(4):747-752.

9. Bell DW, Varley JM, Szydlo TE, Kang DH, Wahrer DC, Shannon KE, Lubratovich M, Verselis SJ, Isselbacher KJ, Fraumeni JF, Birch JM, Li FP, Garber JE, Haber DA: Heterozygous germ line hCHK2 mutations in Li-Fraumeni syndrome. Science 1999, 286(5449):2528-2531.

10. Vahteristo P, Tamminen A, Karvinen P, Eerola H, Eklund C, Aaltonen LA, Blomqvist C, Aittomäki K, Nevanlinna H: p53, CHK2, and CHK1 genes in Finnish families with Li-Fraumeni syndrome: further evidence of CHK2 in inherited cancer predisposition. Cancer Res 2001, 61(15):5718-5722.

11. Meijers-Heijboer $H$, van den Ouweland A, Klijn J, Wasielewski M, de Snoo A, Oldenburg R, Hollestelle A, Houben M, Crepin E, van Veghel-Plandsoen M, Elstrodt F, van Duijn C, Bartels C, Meijers C, Schutte M, McGuffog L,
Thompson D, Easton D, Sodha N, Seal S, Barfoot R, Mangion J, ChangClaude J, Eccles D, Eeles R, Evans DG, Houlston R, Murday V, Narod S, Peretz $T$, et al: Low-penetrance susceptibility to breast cancer due to CHEK2* 1100 delC in noncarriers of BRCA1 or BRCA2 mutations. Nat Genet 2002, 31(1):55-59.

12. Adank MA, Jonker MA, Kluijt I, van Mil SE, Oldenburg RA, Mooi WJ, Hogervorst FB, van den Ouweland AM, Gille JJ, Schmidt MK, van der Vaart AW, Meijers-Heijboer $H$, Waisfisz Q: CHEK2*1100delC homozygosity is associated with a high breast cancer risk in women. J Med Genet 2011, 48(12):860-863.

13. Dong $X$, Wang L, Taniguchi $K$, Wang $X$, Cunningham JM, McDonnell SK, Qian C, Marks AF, Slager SL, Peterson BJ, Smith DI, Cheville JC, Blute ML, Jacobsen SJ, Schaid DJ, Tindall DJ, Thibodeau SN, Liu W: Mutations in CHEK2 associated with prostate cancer risk. Am J Hum Genet 2003, 72(2):270-280

14. Cybulski C, Huzarski T, Górski B, Masojć B, Mierzejewski M, Debniak T, Gliniewicz B, Matyjasik J, Złowocka E, Kurzawski G, Sikorski A, Posmyk M, Szwiec M, Czajka R, Narod SA, Lubiński J: A novel founder CHEK2 mutation is associated with increased prostate cancer risk. Cancer Res 2004, 64(8):2677-2679.

15. Meijers-Heijboer H, Wijnen J, Vasen H, Wasielewski M, Wagner A, Hollestelle A, Elstrodt F, van den Bos R, de Snoo A, Fat GT, Brekelmans C, Jagmohan S, Franken $P$, Verkuijlen $P$, van den Ouweland $A$, Chapman $P$, Tops C, Möslein G, Burn J, Lynch H, Klijn J, Fodde R, Schutte M: The CHEK2 1100delC mutation identifies families with a hereditary breast and colorectal cancer phenotype. Am J Hum Genet 2003, 72(5):1308-1314.

16. Cybulski C, Górski B, Huzarski T, Masojć B, Mierzejewski M, Debniak T, Teodorczyk U, Byrski T, Gronwald J, Matyjasik J, Zlowocka E, Lenner M, Grabowska E, Nej K, Castaneda J, Medrek K, Szymańska A, Szymańska J, Kurzawski G, Suchy J, Oszurek O, Witek A, Narod SA, Lubiński J: CHEK2 is a multiorgan cancer susceptibility gene. Am J Hum Genet 2004, 75(6):1131-1135

17. Teodorczyk U, Cybulski C, Wokołorczyk D, Jakubowska A, Starzyńska T, Lawniczak M, Domagała P, Ferenc K, Marlicz K, Banaszkiewicz Z, Wiśniowski $\mathrm{R}$, Narod SA, Lubiński J: The risk of gastric cancer in carriers of CHEK2 mutations. Fam Cancer 2013, 12(3):473-478.

18. Evans DG, Birch JM, Narod SA: Is CHEK2 a cause of the Li-Fraumeni syndrome? J Med Genet 2008, 45(1):63-64.

19. Walsh T, Casadei S, Coats KH, Swisher E, Stray SM, Higgins J, Roach KC Mandell J, Lee MK, Ciernikova S, Foretova L, Soucek P, King MC: Spectrum of mutations in BRCA1, BRCA2, CHEK2, and TP53 in families at high risk of breast cancer. JAMA 2006, 295(12):1379-1388.

20. Cybulski C, Wokołorczyk D, Huzarski T, Byrski T, Gronwald J, Górski B, Debniak T, Masojć B, Jakubowska A, Gliniewicz B, Sikorski A, Stawicka M, Godlewski D, Kwias Z, Antczak A, Krajka K, Lauer W, Sosnowski M, SikorskaRadek P, Bar K, Klijer R, Zdrojowy R, Małkiewicz B, Borkowski A, Borkowski T, Szwiec M, Narod SA, Lubiński J: A large germline deletion in the Chek2 kinase gene is associated with an increased risk of prostate cancer. J Med Genet 2006, 43(11):863-866.

21. Desrichard A, Bidet $Y$, Uhrhammer N, Bignon YJ: CHEK2 contribution to hereditary breast cancer in non-BRCA families. Breast Cancer Res 2011, 13(6):R119.

22. Sodha N, Williams R, Mangion J, Bullock SL, Yuille MR, Eeles RA: Screening hCHK2 for mutations. Science 2000, 289(5478):359.

doi:10.1186/1471-2407-14-478

Cite this article as: Tedaldi et al:: First evidence of a large CHEK2

duplication involved in cancer predisposition in an Italian family with hereditary breast cancer. BMC Cancer 2014 14:478. 